\title{
La política ferroviaria en el concierto comparado. Apuntes para pensar las políticas públicas
}

Railway policy in the concert compared. Notes for thinking about public policies

A política ferroviária no concerto comparativo. Notas para pensar as políticas públicas

La politique ferroviaire dans l'aspect comparatif. Notes pour réfléchir aux politiques publiques 比较音乐会中的铁路政策。思考公共政策的注意事项

Gabriela Andrea Stortoni ${ }^{1}$ Universidad de Buenos Aires - Argentina

Revista Derechos en Acción ISSN 2525-1678/ e-ISSN 2525-1686

Año 5/NNo 14 Verano 2019-2020 (21 diciembre a 20 marzo), 455-479

DOl: https://doi.org/10.24215/25251678e365

ORCID: https://orcid.org/0000-0001-5324-8833

Recibido: 01/12/2019

Aprobado: 01/02/2020

Resumen: El sistema ferroviario argentino ha seguido cierto derrotero de los sistemas comparados. Por eso la impronta de este estudio es describir algunos lineamientos, los puntos en común que se advierten y las reglas que se pueden adoptar de cara al futuro. La necesidad de un sistema ferroviario fortalecido es troncal en el desarrollo del país. En este sentido, el estudio avanza en describir la evolución del sistema ferroviario en la Europa unida, el régimen el Alemania, Francia, Reino

\footnotetext{
1 Abogada (UNLP), Magister en Derecho Administrativo (Universidad Austral); Master en Administración, Derecho y Economía de los Servicios Públicos de las Universidades Carlos III -Madrid-, París X -Nanterre- Francia y El Salvador -Buenos Aires, Argentina; docente de Derecho Administrativo en la Universidad de Buenos Aires y Universidad Austral.
} 
Unido, España, Estados Unidos, América del Sur y Japón. El objetivo de abrir el debate y promover el estudio y el pensamiento. El desafío es pensar una solución vernácula, aprendiendo de las experiencias comparadas y de la propia historia del sector.

Palabras claves: transporte ferroviario. Sistema Comparado. Separación vertical.

Abstract: The Argentinean railway system has followed a certain path of comparative systems. Therefore, this study describes some guidelines, the common points and the rules that can be adopted in the future. The need for a strengthened railway system is central to the country's development. In this sense, the study advances in describing the evolution of the railway system in the United Europe, the regime in Germany, France, United Kingdom, Spain, United States, South America and Japan. The aim is to open the debate and promote study and thought. The challenge is to think of a vernacular solution, learning from comparative experiences and the history of the sector itself.

Keywords: rail transport. Comparative System. Vertical separation.

Resumo: 0 sistema ferroviário argentino seguiu certo curso dos sistemas comparados. Por isso o objetivo deste estudo é descrever algumas diretrizes, os pontos comuns observados e as regras que podem ser adotadas de cara ao futuro. A necessidade de um sistema ferroviário fortalecido é central para o desenvolvimento do país. Nesse sentido, 0 estudo avança na descrição da evolução do sistema ferroviário na Europa unida, o regime na Alemanha, França, Reino Unido, Espanha, Estados Unidos, América do Sul e Japão. 0 objetivo de abrir o debate e promover 0 estudo e o pensamento. 0 desafio é pensar uma solução vernácula, aprendendo das experiências comparativas e da própria história do setor.

Palavras-chave: transporte ferroviário. Sistema Comparativo. Separação vertical

Résumé:Le système ferroviaire argentin a suivi un certain parcours des systèmes comparés. C'est pour cela que l'idée de cette étude est de décrire quelques lignes directrices, les points communs qui sont remarqués et les règles qui peuvent être adoptées pour l'avenir. Un système ferroviaire renforcé est essentiel au développement du pays. En ce sens, l'étude avance dans la description de l'évolution du système ferroviaire 
en Europe unie, en Allemagne, en France, au Royaume-Uni, en Espagne, aux États-Unis, en Amérique du Sud et au Japon. L'objectif est d'ouvrir le débat et de promouvoir l'étude et la réflexion. Le défi est de penser à une solution vernaculaire, en apprenant des expériences comparatives et de l'histoire du secteur.

Mots clés: transport ferroviaire. Système comparatif. Séparation verticale.

摘要：阿根廷铁路系统遵循了比较系统的特定过程。因此, 本研究的 重点是描述一些准则, 注意的共同点以及将来可以采用的规则。加强 铁路系统的需求对国家的发展至关重要。从这个意义上说, 研究在描 述欧洲铁路系统的发展, 德国, 法国, 英国, 西班牙, 美国, 南美和日本 的政权发展方面取得了进展。开放辩论和促进学习与思考的目的。面 临的挑战是想一个白话方案, 从比较经验和行业本身的历史中学习。 关键词：铁路运输, 比较系统, 垂直分离

\section{Introducción}

Cuando pensamos como recuperar el sector ferroviario argentino, castigado tantas veces, y usado otras tantas como emblema, ya para intereses economicos sectoriales sembrados de ideologias mezquinas, creo que resulta conveniente, dar un repaso por algunos sistemas ferroviarios en el concierto comparado.

\section{Europa y las reglas de la Unión Europea}

Europa es el continente que posee mayor cantidad de kilómetros de vías férreas en relación con su superficie $(4 \mathrm{Km}$. por cada $100 \mathrm{~km} 2$ ). La mayor densidad se encuentra en los países más densamente poblados. En Europa occidental gran parte de los ferrocarriles cuentan con vías electrificadas, como en Suiza, Austria, Italia, Suecia, etc., y grandes obras de ingeniería, especialmente en los Alpes. Así se levanta como icono de la obra publica, la construcción del "Eurostar" que permite unir París con Londres en solo tres horas. 
Los países de Europa, no obstante, no acreditan el mejor crecimiento en términos de carga transportada y rentabilidad en el transporte de pasajeros. Dice la OCDE que los países europeos tienen ganancias muy por debajo de los Estados Unidos, ${ }^{2}$ por lo cual de cara a ganar sustentabilidad económicofinanciera se instrumentara en Europa una política ordenada a la compatibilización de las redes férreas, para el crecimiento sostenido de los países miembros.

Por ello "el modelo de transporte supone, además de la aportación de sus peculiares calidades, la reasunción del transporte ferroviario desde una perspectiva renovada, como sistema racionalmente capaz de salvar la situación de agotamiento y los efectos indeseables que ofrecen hoy el transporte por carretera y el espacio aéreo, precisamente por causa de su enorme crecimiento y saturación ${ }^{3 "}$.

El uso del tren y el abandono del automóvil sólo pueden ser estimulados con una gestión competitiva en todos los sentidos que sea capaz de ganarse la potencial población de pasajeros que harían noble el mantenimiento del servicio.

Y la vocación de la creación de redes ferroviarias integradas es uno de los objetivos de la Unión Europea.

Como dice Parejo Alfonso "La política comunitaria en materia del ferrocarril estuvo así dirigida desde sus inicios a abrir el mercado hacia la competencia, en cuanto instrumento idóneo para su desarrollo. La primera dificultad estribaba en que en la mayoría de los Estados miembros el servicio de transporte ferroviario era un monopolio. La segunda era la grave situación

\footnotetext{
2 OECD. "As an ilustration, the average revenue per employee of freigth transport services by railways of Britain, France, Italy and Germanyin 1994 was between $\$ 43.000$ for France and 519.500 for Italy, compared with $\$ 155.000$ in the US", end Railways: Structure, Regulations and Competition Policy, DAFFE/CLP/(98) Competition Policy. Les tatoles sur les politiquees cíe concurrence, nro. 15, OECD, www.oecd.org, diciembre 2001.

3 LÓPEZ MENUDO, Francisco, "Las infraestructuras ferroviarias europeas. Cuestiones competenciales" en MONTORO CHINER, Mana Jesús (coorci.), Infraestructuras ferroviarias del Tercer Milenio, Cedecs, Barcelona - España -1999.
} 
de crisis financiera que afectaba a las empresas nacionales encargadas de la gestión del servicio ferroviario. Estas dos trabas originaron que los dos objetivos centrales de las medidas comunitarias adoptadas fueran la apertura progresiva a la competencia y el saneamiento de las empresas ferroviarias" primeras medidas fueron de restricción a las reglas de la competencia lisa y llana que podrían ser aplicadas en otros sectores, de cara a asegurar la continuidad y regularidad del servicio.

Por eso, se restringió, por el Reglamento 141/1962/CEE del 26 de noviembre de 1962, la aplicación al sector de los transportes del Reglamento 17/1962/CEE del 6 de febrero de 1962, que desarrollaba el régimen de la competencia establecidos en la Tratado de la Comunidad Europea, como medida de protección de un sector que primero debe crecer para abrirse a la competencia. Ello también resultara del propio Tratado de Roma, que autorizo a los servicios de transporte contar con regímenes de ayudas publicas, en forma mas flexible que otras áreas, por el servicio publico a garantizar. ${ }^{5}$

Por su parte, el art. 129.B) del Tratado de Roma, expresa que a fin de contribuir a la realización de los objetivos contemplados en los arts. 7 y 130 del tratado y para permitir que los ciudadanos de la Unión, los operadores económicos y los entes regionales y locales participen plenamente de los beneficios resultantes de la creación de un espacio sin fronteras interiores, la Comunidad contribuirá al establecimiento y al desarrollo de redes transeuropeas en los sectores de las infraestructuras de transportes, de las telecomunicaciones y de la energía.

\footnotetext{
4 PAREJO ALFONSO, LUCIANO (Director) y otros "ESTUDIOS SOBRE LA ORDENACION DEL SECTOR FERROVIARIO EN LA UNION EUROPEA (EI marco comunitario y los casos alemán, francés, británico y español)" Instituto Pascual Madoz del Territorio, Urbanismo y Medio Ambiente. Universidad Carlos III de Madrid, con la colaboración de la Fundación de Ferrocarriles Españoles. Madrid, España, 2004. Pagina 21

5 La Decisión 1965/271/CEE del Consejo del 13 de mayo de 1965, establece que "las obligaciones inherentes a la noción de servicio publico impuestas a las empresas de transporte, solo deberían mantenerse en la medida que su mantenimiento sea indispensable para garantizar la prestación de los servicios de transporte suficientes"
} 
Y sigue diciendo que - en el contexto de un sistema de mercados abiertos y competitivos - la acción de la Comunidad tendrá por objetivo favorecer la intercomunicación e interoperabilidad de las redes nacionales, así como el acceso a dichas redes. Tendrá en cuenta, en particular, la necesidad de establecer enlaces entre las regiones insulares, sin litoral y periféricas, y las regiones centrales de la Comunidad.

Asimismo, el art. 129.C reafirma la importancia del desarrollo de proyectos de interoperabilidad de trenes y dice que "la acción de la comunidad tendrá en cuenta la viabilidad económica potencial de los proyectos".

A estas normas se suma la directiva 440/1991 del Consejo de 29/7/1991, la cual, bajo el título "Desarrollo de ferrocarriles comunitarios", en su art. $1^{\circ}$, enuncia los objetivos fundamentales, a saber:

- Garantizar la autonomía de gestión de empresas ferroviarias. Implica que cada empresa cuente con un Estatuto independiente de los Estados, que sean administradas como sociedades privadas; que tengan programas de actividad, inversión y financiación orientados al equilibrio financiero; que se garantice la libertad de asociarse con una o más empresas privadas para conformar una agrupación internacional; fijar sus tarifas, tornar decisiones respecto de su personal y activos propios. En otras palabras, la apertura al mercado del servicio y adopción de formas societarias liberales ${ }^{6}$.

- Separación de la gestión de las infraestructuras y de la explotación de los servicios de transporte de las empresas ferroviarias, siendo obligatoria la separación contable y voluntaria la separación orgánica o institucional. Implica además que puedan ser gestiones y empresas diferentes:

\footnotetext{
6 La Directiva 237 del 29/7/1991, sobre el Desarrollo de los Ferrocarriles Comunitarios, expresa que "...a efectos de que los transportes por ferrocarril sean eficaces y competitivos con respecto a los demás medios de transporte, los Estados miembros deben concederá las empresas de transporte ferroviario un régimen de empresa independiente que les permita actuar con arreglo a criterios comerciales y adaptarse a las necesidades del mercado".
} 
se promueve la financiación pública para el desarrollo de la infraestructura exclusivamente; el administrador de la infraestructura tendrá derecho a aplicar un canon no discriminatorio a las empresas ferroviarias que sean operadores de cargas nacionales o internacionales y que se sirvan de dicha infraestructura ${ }^{7}$.

- Saneamiento de la infraestructura financiera de las empresas ferroviarias. Los Estados miembros y las empresas establecerán mecanismos para contribuirá reducir las deudas de dichas empresas.

- Garantizar el acceso a las redes ferroviarias de los Estados miembros para las agrupaciones internacionales de empresas ferroviarias, así como para las empresas ferroviarias que efectúen transportes combinados internacionales de mercancías.

Este escenario impacto de lleno en los diferentes Estados de la Unión, con variopinto resultado, el que veremos a continuación, pero es claro que las reglas de recuperación del sector con ayudas publicas que se orienten a una visión confederada de las redes: la impronta del necesario saneamiento de las empresas a cargo del servicio, mas allá de lo publico o lo privado; y la necesaria diferenciación de las unidades de los negocios, por ejemplo, infraestructura por un lado y servicios por el otro, van a ser reglas que marcarán la agenda planificada y de largo plazo. No es menor el lugar que se le da al servicio publico en esta materia, y de su definición, como asistencia de la necesidad general, se impone garantizar su prestación, antes que nada.

\footnotetext{
7 No olvidamos que esta pauta tiene su antecedente en el sistema sueco. En efecto, Suecia ha sido la primera nación que aplica el sistema de separación vertical, entre infraestructura y operación de servicios. Ello ocurre mediante el dictado de la ley de Suecia de 1988, la cual separó el monopolio ferroviario estatal, Statens Jarnvagar, en dos organizaciones distintas. Las operaciones de tráfico están actualmente administradas por la nueva empresa Statens Jarnvagar (SJ), que sigue siendo en lo esencial una concesión monopólica de propiedad del Estado. La responsabilidad del mantenimiento y la construcción de la infraestructura ferroviaria ha sido transferida a una nueva organización estatal, la Banverket (Administradora Nacional de Vías Férreas).
} 
Y en este escenario, cuatro paquetes de leyes y directrices ferroviarias van a delinear las reglas europeas de la integración para la creación de una red transeuropea. Entonces, separación entre infraestructura y servicios, homogeneización de la red, introducción de la figura de la licencia, reglas uniformes en materia de prestación del servicio para su eficiencia, pero también para su seguridad, van a ser las líneas mas destacadas.

A esto se suma, para mejorar la interoperabilidad y la seguridad del sistema ferroviario europeo, la Agencia Ferroviaria Europea (AFE) creada por el Reglamento (CE) n. ${ }^{\circ} 881 / 2004$, de 29 de abril de 2004. La principal función encomendada a esta Agencia es la de armonizar, registrar y supervisar las empresas de transporte de todo el sistema ferroviario europeo y establecer objetivos comunes de seguridad para los ferrocarriles europeos.

Hoy la AFE, por impacto del cuarto paquete ferroviario y mediante el Reglamento (UE) 2016/796, es la institución competente para emitir autorizaciones de vehículos (locomotoras y vagones) destinados a actividades transfronterizas, así como certificados de seguridad únicos para las empresas ferroviarias que operan en varios Estados miembros.

La idea entonces de crear un espacio homogéneo y seguro, con autoridades europeas independientes, y sistemas de acceso transparentes van a ir desarrollando el proceso de crecimiento ferroviario europeo.

Veamos ahora el desarrollo ferroviario en algunos de los países mas importante de Europa.

\section{Alemania}

Los trenes empiezan a desarrollarse en Alemania a principios de 1835. El crecimiento no fue uniforme y fue de impronta publica, como tambien del sector privado.

Ello fue asi hasta en el año 1919, con la Constitucion de Weimar se declara que el ferrocarril es de competencia federal. En 1924 se crea la Deustche Reichsbahn Gessellschaft (DRG) 
como empresa publica tipo FERROCARRILES ARGENTINOS y con monopolio durante 40 años

Con la segunda guerra mundial en ciernes, en 1937, la DRG es disuelta por el Gobierno quien pone en cabeza del Ministerio de Transporte la gestión de los servicios.

Finalizada la segunda guerra mundial, se constituyen dos sociedades ferroviarias en cada República, los cuales se unificaran en 1993 con la caida del Muro de Berlin y la unificacion alemana.

Se crea la Deustche Bahn A.G.(DB) sociedad anónima de capital estatal, en un principio, a cargo de la infraestructura y la prestación de los servicios y la BEV a cargo del patrimonio ferroviario y el personal (régimen previsional y de jubilaciones)

La privatización llegara a la DB en 1999, la que se divide en cinco empresas, a saber:

- Una para el largo recorrido

- Otra de cercanías

- Otra de carga

- Otra de infraestructura

- Y finalmente otra para las estaciones.

El sistema se completa con la EBA que era el organismo de control del sistema, creada en 1994, la cual tendrá a su cargo todo lo atinente al control y autorización de la red ferroviaria federal alemana y de los landers, previa delegación de competencia.

El sistema alemán, en esta instancia llega a tener mas de 300 empresas ferroviarias autorizadas como prestadores de servicios, y si bien la infraestructura ferroviaria queda principalmente en cabeza de la DB, la posibilidad de acceder a la administración de infraestructura se regula expresamente. La autorización es otorgada por la EBA y puede ser de 15 años para los operadores de servicios y de 50 para los que administren infraestructuras.

La separación vertical es obligatoria en la separación contable, requisito sine qua non de las empresas que tengan ambas autorizaciones de servicios y de infraestructura. 
En la práctica el Estado va a sostener la inversión en infraestructura ferroviaria, mientras que las ayudas y subsidios se evitaran en la prestación de servicios ferroviarios a cargo de privados, a los fines de garantizar que se trate de negocios privados fidedignos.

Hoy el sistema ferroviario alemán presenta una marcada presencia de la DB en la prestación de los servicios de pasajeros urbanos y de cercanías, y de transporte de mercaderías, pero también existe una importante competencia.

No obstante, se ha considerado que la separación vertical, como política publica, se encuentra en jaque en Alemania $^{8}$, y eso de por si genera ciertos incentivos para volver a pensar en una empresa que contengan todas las unidades de negocios del sistema ferroviario (en nuestro ámbito, volver a FA).

No creo que sea ello conveniente, desde que, en Alemania, la competencia esta presente en todos los segmentos, aun cuando se reconozca el protagonismo de la DB. En segundo lugar, la separación vertical es una obligación en materia contable y se impone como precepto de la UE. Su incumplimiento generará responsabilidad ante la Unión, y ello seria un costo muy alto. Distorsiones puntuales las hay, como en todo sistema, pero las excepciones no pueden ser la vara de medición.

También se juegan otras cuestiones aquí, como las buenas practicas y a la responsabilidad por "accountability" o cuentas claras.

En tercer termino, la presencia de la Agencia de Redes, que desde el año 2005, con la nueva Ley General Ferroviaria, se incorpora a estos servicios bajo su competencia de control de monopolios, que le da nuevos aires a la separación vertical.

8 Ver Documento No 4 "El open access en el transporte ferroviario en Alemania. Logros a mitad de camino." Marcelo E. Lascano. Serie Análisis de Políticas y Planificación del Transporte 2016 http://www.unsam.edu.ar/institutos/transporte/publicaciones/documento \%20 4 \%20lascano \%20el \%20open \%20acces \%20alemania.pdf 


\section{Francia}

La construcción de los ferrocarriles en Francia se inicia en 1831 con la primera línea de cargas y en 1834, con las servicios para pasajeros. El negocio privado que generaba el ferrocarril es la razon de su nacimiento, al igual que en otras latitudes y paises.

La red fue diseñada en 1842 mediante una estrella de cinco puntas denominada Legrand. Y en 1914 alcanzó la longitud de 40 mil kilometros. El sistema original era concesional con tarifas reguladas.

En 1937, en epoca tambien cercana a lo que va a acontencer diez años despues en nuestro país, se nacionalizaron los ferrocarriles franceses mediante la creación de la compañía mixta SOCIETE NATIONALE DE CHEMIN DE FER FRANCAIS conocida por sus siglas SNCF. El servicio estaba a cargo del Estado, altamente subsidiado y el crecimiento va a tener una impronta mayuscula con la tecnologia de los aviones concorde, que se trasladara a los trenes de alta velocidad. En efecto, en 1981 se inaugura la red de alta velocidad TGV, en la línea París - Lyon.

En los últimos años de las décadas de 1990 y 2000 se implantan las reformas previstas por la Unión Europea, entre las que se encuentra la separación entre infraestructura y explotación, lo que llevó a la creación de Réseau ferré de France (RFF) en 1997 y a la separación de las actividades de la SNCF en tres departamentos: Grandes Líneas y Transporte Público para pasajeros; Mercancías e Infraestructura. En este último departamento, Réseau ferré de France delega la explotación y el mantenimiento de la red. El 1 de enero de 2015 nace SNCF Réseau como consecuencia de la fusión de Réseau ferré de France (RFF), SNCF Infra y Direction de la circulation ferroviaire (DCF).

Con el actual gobierno de Macron, de corte liberal, se pretende implementar privatizaciones de algunos sectores del servicio ferroviario que aunque separado contablemente, esta en manos del Estado. Veremos que sucede. 


\section{Reino Unido}

En Inglaterra, por su parte, es sabido que la historia de los ferrocarriles ha recorrido diversas adecuaciones contractuales, e idas y vueltas de titularidad estatal y privada.

Es el país con más antigüedad en la materia, que comenzó su desarrollo mediante la aparición de numerosas compañías privadas, que desarrollaban líneas y servicios, durante el siglo XIX, a partir de 1820, considerada como la railwaymanía, por la especulación en la compra y desarrollo privado de los ferrocarriles.

La red conformada por 130 compañías privadas, se unifican en 1920, en cuatro empresas, denominadas las big four e identificadas como:

- GREAT WESTERN RAILWAY

- LONDON AND NORTH EASTERN RAILWAY

- LONDON, MIDLAND, AND SCOTTISH RAILWAY

- THE SOUTHERN RAILWAY

La explotación ferroviaria siguió hasta 1947. La TRANSPORT ACT DE 1947 pone el sistema bajo la tutela de la BRITISH TRANSPORT COMISION, que en el gobierno laboralista pretendió crear un sistema integrado y centralizado. Un año más tarde la bancarrota llego a las compañías y se decidió la NACIONALIZACION en THE BRITISH RAILWAYS.

Este panorama se mantiene hasta los años 60, cuando se crea una sociedad prestadora del servicio denominada BRITISH RAILWAYS. La empresa irá perdiendo protagonismo y credibilidad hasta 1992, que será objeto de privatización, siguiendo las recomendaciones del denominado Libro Blanco de los Ferrocarriles, abriendo el sector a la competencia, con separación vertical y horizontal. En consecuencia, el 1 de abril de 1994, la BR se divide en RAILTRACK, a cargo de la administración de la infraestructura ferroviaria y The Operating Company.

El sistema se completa con la OFFICE OF PASSENGER RAIL FRANCHISING que es la encargada de adjudicar las franquicias, bajo la égida del DIRECTOR OF PASSENGER RAIL FRANCHISING. 
A cargo del control se crea la RAIL REGULATOR 9 . Por otro lado, para la planificación y con potestad para otorgar franquicias, se crea la STRATEGIC RAIL AUTHORITY, y para la regulación, la OFICCE OF RAIL REGULATOR, como autoridad independiente. El panorama de las entidades publicas se complementa con THE HEALTH AND SAFETY EXECUTIVE, que tiene a su cargo la seguridad en material laboral e interviene en accidentes; la BRITISH RAILWAYS BOARD, un organismo residual encargado de la administración y venta de terrenos ferroviarios no operativos y la RAIL SAFETY AND STANDARDS BOARD (creada en 2003 luego del accidente fatal de Landbroke Grove, a cargo seguridad en materia ferroviaria)

Inglaterra ha aplicado el sistema de separación vertical de infraestructura y servicios, dejando la primera en manos de una sola compañía privada; y los segundos en manos de diversas compañías. Hoy, el mercado del transporte de pasajeros está medianamente desregulado, en tanto se permite el acceso de nuevos operadores de servicios, siempre que se trate de una actividad sustentable y un corredor sin prestación actual; mientras que en el mercado ferroviario de cargas el acceso está totalmente desregulado. Ahora bien, contrariamente a lo que se predica del sector ingles y su apertura a lo privado, el ferrocarril inglés tiene una alta presencia publica, en administración de infraestructura y en la multiplicidad de organismos de control y de administración publica.

La infraestructura actualmente esta en manos de una empresa privada de capitales principalmente publicos, bajo regimen privado pero sin fines de lucro, denominada NETWORK RAIL. No obstante, conviven 26 empresas licenciatarias de pasajeros y 4 operadores de mercancias. Se puede acceder a licencias para operar estaciones, almacénes y logística.

Las empresas interesadas en prestar servicios de transporte en el sistema ingles deben obtener:

9 Fuente; OECD, Railways: Structure, Regulations and Competition Policy..., Op. cit. 
1. Acuerdo de acceso con el operador de la red, sujeto a la aprobación de la autoridad de aplicación correspondiente.

2. Obtención de una Franquicia para explotar un servicio.

3. Licencia de Operador

No obstante, el sistema ingles -señero en el desarrollo de los ferrocarriles y símbolo de la revolución industrial y las avanzadas en las políticas aplicadas en la materia- presenta muchas criticas ya que no paso por una buena racha desde la privatización.

El modelo de separación vertical y horizontal se empañó con la burocratización de las instituciones - demasiadas por cierto con competencias que se solapan en muchos de los casos. A ello, la politización y los accidentes ferroviarios, hicieron que el sector sufra el vapuleo de la opinión pública casi constante.

\section{España}

En España, por su parte, y como modo de adaptarse al imperativo comunitario impuesto por la directiva 440/1999, el Real Decreto Nro. 121/1994 que establece el nuevo Estatuto de Renfe proclama que "es la idea plasmar las nuevas técnicas de gestión y administración de las sociedades públicas, regulando la prestación y explotación del servicio público del transporte ferroviario como una entidad distinta del Estado, en quien reside la titularidad de aquél", y en consecuencia, atribuye al Renfe facultades distintas y separadas: por un lado, de administración de la infraestructura y, por otro, de explotación de los servicios ${ }^{10}$.

Por otro lado, el Real Decreto 613/1997 del 25 de abril aprueba el Estatuto para el Ente Público Gestor de Infraestructuras

\footnotetext{
10 Corresponde a Renfe: 1) El mantenimiento de las líneas ferroviarias, en los términos acordados con la Administración Pública titular de las mismas. 2) La gestión de los sistemas de regulación y segundad del tráfico. 3) La construcción de nuevas líneas ferroviarias. 4) La explotación mediante el cobro del correspondiente canon, de las líneas que formen par te de la Red Nacional Integrada y de aquellas otras cuya gestión le sea encomendada por la Administración Pública titular de las mismas, pudiendo exigir la adecuada contraprestación económica. 5) La explotación de los servicios de transporte ferroviario que formen parte de la RNI y de aquellos cuya gestión le sea encomendada.
} 
Ferroviarias (GIF), creado por la Ley del Acompañamiento 13/1996 del 30 de diciembre, al que se encomienda "la construcción y, en su caso, explotación de las nuevas infraestructuras ferroviarias que expresamente le atribuya el Gobierno, incluida la electrificación y señalización" (Renfe ha de aportar la tracción y abonar a GIF el canon por la explotación de las líneas nuevas).

El sistema español se basa en:

1. Una Red Nacional de Infraestructura a cargo del Estado y sufragado con presupuestos generales; que a su vez ostenta la explotación de líneas preexistentes resultando las nuevas líneas a cargo del GIF.

2. Monopolio de cada red, con derecho de acceso y tránsito por parte de terceros.

3. Una nueva dinámica de reparto de competencia entre el Estado y las Comunidades Autónomas en materia de transporte por ferrocarril.

4. Aparece el concepto de canon, sin vinculación a una ecuación - como resulta de nuestras normas de concesión-, sino como pieza instrumental al servicio de la creación de un mercado común ferroviario que - regido por pautas de libre competencia- coadyuve a los objetivos de cohesión e integración que preside el proyecto político, social y económico de la Unión Europea, esto es, canon como derecho de utilización de la infraestructura ${ }^{11}$.

Como expresa López Menudo ${ }^{12}$, el sistema español, por el monopolio en manos de Renfe y GIF, presentaba una regulación que no era acorde con las normas comunitarias, no obstante mencionar su cumplimiento y espíritu orientador de las normas, hasta que se dicta el REAL DECRETO 39/2003.

\footnotetext{
11 Este canon se determina por las siguientes variables, a saber: naturaleza del servicio; duración del servicio; situación del mercado; naturaleza y deterioro de la infraestructura, y razones de eficacia comercial.

12 En igual sentido para America Latina ver CEPAL, Restructuración y privatización de los ferrocarriles" op. p. 27. https://repositorio.cepal.org.
} 
Esta norma introduce la separación de la red de interés general (federal) de las redes autonómicas, asigna la administración de la infraestructura a cargo de una administración pública estatal, denominada ADIFSE, y deja la operación de servicios a cargo de la emblemática empresa publica RENFE, rebautizada ahora, RENFE OPERADORA.

Así da cumplimiento al mandato de la UE de la separación vertical y apertura de los servicios a la competencia. En el año 2006, se abre el registro de prestadores de servicios d mercancía por ferrocarril, mientras que la apertura del servicio de pasajeros esta aun pendiente.

Al igual que en el sistema ingles, se van a introducir los regímenes de acceso a la prestación del servicio a través de Licencias, similares a las autorizaciones administrativas. Para poder acceder a la red, se establecen las reglas de adjudicación de capacidad de vía, tarifa razonable y el canon por uso de la infraestructura.

\section{Estados Unidos}

En los Estados Unidos, la historia del ferrocarril se inicia a principios del siglo XIX, mediante su construcción por parte de empresarios ingleses y locales. Su rol fue fundamental, configurando la tecnología más influyente del siglo XIX. Sus contribuciones fundamentales al avance de los transportes y las comunicaciones sentaron las bases de un amplio impacto social y económico sobre dos de las más poderosas tecnologías que siguieron al ferrocarril: el automóvil y el ordenador o computadora informática.

Hoy sigue siendo un servicio líder en el segmento de las mercancías, transportando el 40 por ciento. El ferrocarril es en Estados Unidos el emblema del desarrollo, como lo es en Argentina, y recuerda la conquista del Oeste, uniendo los pueblos y achicando las distancias, diríamos parafraseando a Alberdi.

El legado de los ferrocarriles en Estados Unidos, no obstante, se destaca desde otra mirada, que es haber sido una herramienta 
de unificación política y social del País, En esto evoca la conquista del Oeste, con todas las connotaciones añadidas a la idea de vida americana y su ética de construcción del espacio nacional. En 1830, primer año de funcionamiento del ferrocarril en los Estados Unidos, todas las tierras que se convertirían dos décadas más tarde en territorio norteamericano tenían una extensión territorial que significaba 30 veces la extensión de Gran Bretaña, aunque el tamaño de la población era mucho menor.

Aunque constituye un tópico afirmar que, desde la perspectiva de los Estados Unidos, la empresa privada es preferible a la intervención del Estado, los diferentes gobiernos en todos sus niveles, desde el municipal al federal, desempeñaron un papel crucial en la construcción de infraestructura de transporte. En la construcción de las redes ferroviarias la financiación y las subvenciones en forma de tierras por parte de la administración serian importantes, aunque no decisivas, alcanzando el 25 por 100 del total de inversiones en 1860. La cantidad restante procedió de acaudalados particulares, muchos de ellos europeos, ingleses fundamentalmente.

Otro dato interesante del desarrollo ferroviario americano es que, si bien al comienzo dependieron fuertemente de la tecnología y el material inglés, tempranamente desarrollaron una industria nacional capaz de construir y poner en marcha ferrocarriles adecuados a las especificas condiciones de los Estados Unidos.

Y fue más innovadora que la inglesa, a la cual tributaba. En este punto la industria fue capaz de generar innovaciones para construir ferrocarriles, adaptando las locomotoras y los carriles a las necesidades del terreno y a las condiciones del entorno físico.

Es curioso cómo la grieta que se genera en Estados Unidos por la devastadora Guerra de Secesión (1861-1865) encuentra en el ferrocarril la herramienta para reconstruir la unidad de la Nación.

El desarrollo de la red ferroviaria fue extraordinario y antes de la entrada de los Estados Unidos en la I Guerra Mundial, el conjunto del sistema ferroviario sobrepasaba los 400.000 
kilómetros. Como ocurrió en todo el mundo, será décadas después, con la aparición del automóvil y el camión y la construcción masiva de autopistas, cuando se desata el gran reto frente a la prevalente preponderancia del ferrocarril en el transporte de superficie en los Estados Unidos.

El crecimiento ferroviario, no obstante, se va a ver empañado por las luchas en materia tarifaria y la colusión empresaria. Las leyes de los Estados Unidos han sido históricamente mucho más hostiles a los carteles que las europeas; y los esfuerzos para regular los precios han provocado una mayor oposición política y jurídica. Dado que los ferrocarriles eran en muchos casos monopolios privados, se convirtieron en la primera industria sujeta a regulación, inicialmente al nivel de los Estados considerados individualmente y después por el Gobierno federal.

Es este otro dato importante del desarrollo americano. La primera agencia reguladora federal fue la Comisión Comercial Interestatal, fundada en 1889. También se destaca que fueron pioneros en poner en marcha la empresa moderna y la gran corporación típica de los Estados Unidos. Los ferrocarriles fueron el primer sector en crear medios para gestionar e innovar con los grandes volúmenes de datos, recursos y personal que debía manejar. Fueron también las compañías de ferrocarril pioneras en la creación de un grupo de directivos y de estructuras organizativas descentralizadas que más tarde serian adoptadas en otras grandes empresas de otros sectores de la economía.

Ahora bien, en el período que va desde el año 1947 hasta 1970, el nivel de carga transportada en los Estados Unidos cae a un $31 \%$, y el número de pasajeros, al dramático porcentaje de $84 \%$, debido, según la OECD, a la fuerte regulación de la Interestate Commerce Commission (ICC), que requirió la publicidad y generalidad de las tarifas y el sostenimiento de líneas que no eran rentables, por un lado; y, por otro, al programa federal de construcción de autopistas ${ }^{13}$.

13 Lamentablemente, en la Argentina, las crisis no tienen ese efecto de regeneración de sistema que ocurre en otros países. Otra solución post crisis fue la recuperación del sistema 
Para salir de la crisis, en 1970 se dicta la Rail Passenger Service Act, que creó la Corporación Nacional de Trenes de Pasajeros, conocida bajo el nombre de $A_{m}$ trak $^{14}$, que es la única empresa estatal prestadora de servicios de transporte ferroviarios. Asimismo, el Gobierno procedió a desregular el servicio de transporte de cargas en 1980. Estas empresas comparten infraestructura a cambio del pago de un canon de acceso. Amtrank con esos ingresos mejora los niveles de ingresos de una red de pasajeros, siempre considerada deficitaria ${ }^{15}$.

\section{América del Sur}

El primer ferrocarril de Iberoamérica va a inaugurarse en Cuba, todavía española, en el año 1837. Recién a partir de 1850 este modo de transporte comenzará su gran expansión en América Latina ${ }^{16}$, en un momento en que el continente estaba inmerso en las luchas intestinas por la independencia y las crisis financieras de los años 1825-1826.

ferroviario en Bangkok, Tailandia, luego de la crisis de 1997, lo que impulsó a aplicar políticas de integración de los modos y fortalecimiento de los servicios públicos de transporte a los fines de evitar los costos que generaba el uso del auto particular, y redujo de ese modo el uso de combustible (Fuente: Country Report, "Transporte Strategies en Bangkok after economic crisis", 1998, JICA, Japón).

14 Esta empresa, desde sus inicios, se esforzó por modificar varios aspectos que conspiraban contra la calidad de los servicios y la viabilidad económica de los mismos. En primer lugar, negoció nuevos contratos de trabajo con los sindicatos del personal de los trenes y de los maquinistas, alcanzando su mayor éxito cuando éstos aceptaron el pago de ocho horas por el trabajo de ocho horas en lugar de hacer que el recorrido de 100 millas se considerara equivalente a ocho horas trabajadas. Así, en un esfuerzo permanente por aplicar métodos de racionalización como empresa privada con objetivos comerciales, Amtrak, que en 1976 apenas cubría el $42 \%$ de sus costos con ingresos propios, actualmente autofinancia el $80 \%$ de sus operaciones.

15 OECD. Railways: Structure, regulation and Competition Policy. 1997. https://www.oecd. org/daf/competition/sectors/1920239.pdf.

16 Brasil, Argentina y México van a llegar en 1945 al 75 \% del tendido ferroviario de la América Latina, lo cual contribuyó a convertirlos en tres países líderes de Latinoamérica; no obstante, fue por aquellos años cuando los ferrocarriles comenzaron a ser deficitarios, dando paso al transporte por carretera, tanto de pasajeros como - y sobre todo- de mercancías. 
Europa, entonces, hizo el segundo y real "descubrimiento" de América, especialmente para los comerciantes británicos.

Ahora bien, no obstante su origen mercantil, la figura del ferrocarril no va a representar nunca un ícono de la propiedad privada liberal ${ }^{17}$ por que la necesidad de su servicio va a legitimar su existencia, como debito al usuario del servicio y patrimonio del ciudadano.

Esa impronta seguirá apareciendo al alternarse las políticas de ampliación o reducción del Estado, que va a pasar de observador a propietario y de ahí a privatizador/concedente y entonces regulador del sistema. Y ello en un corsi y ricorsi, esa idea italiana ${ }^{18}$ que entendía que la historia no avanza de forma lineal empujada por el progreso, sino en forma de ciclos que se repiten, es decir, que implican avances y retrocesos, como un obligado aprendizaje de los errores cometidos anteriormente.

En América latina, casi al mismo tiempo que en la Argentina, en las cercanías o albores de la década del 90 se produce la reestructuración de los ferrocarriles, pasando los mismos a manos privadas, tal el caso de Brasil, Bolivia, etc.

No obstante, en algunos casos, es interesante destacar algunas alternativas de la gestión que fueron aplicadas.

En Chile, por ejemplo, la primera locomotora empezó a correr en 1852 y se estima que hoy cuenta con una longitud total de $10.000 \mathrm{Km}$. de vías. Nacido bajo un sistema de capitales

17 Esta dialéctica como expresa Jesús Sanz Fernández en la obra colectiva "HISTORIA DE LOS FERROCARRILES DE IBEROAMERICA (1837-1995) en relación a los albores de la construcción del ferrocarril en Cuba, que es el primero por cierto, que "...el ferrocarril en Cuba como en otros países, habría de ser un negocio privado, pero a tenor de la envergadura de las inversiones y esfuerzos que precisaba su construcción, exigía de la protección, del impulso y de la ayuda de las instancias gubernamentales para llegar a ser una realidad. Con el paso del tiempo esta convicción llego a ser un lugar común en la mayoría de las republicas iberoamericanas - no en todas - y termino teniendo una serie de implicaciones para las empresas ferroviarias que acentuaron su singularidad e hicieron difícil, desde el comienzo, deslindar claramente lo publico de lo privado en la implantación y desarrollo de esa actividad mercantil". P. 45. Ed. Ministerio de Fomento. Reino de España, 1998.

18 Acuñada por el filósofo e historiador Giambattista Vico, quien vivió entre 1668 y 1744. 
privados, el ferrocarril pasó por etapas de desarrollo y decepción, inversión y abandono, hasta que en 1989 la crítica situación obligó al Gobierno a pensar en la reestructuración de los ferrocarriles. A diferencia de otras experiencias americanas, “...el Estado chileno permaneció activo en cuanto a responsabilidades directas de operación y control, sin perjuicio de integrar la reforma con transferencias al sector privado de otras responsabilidades" 19 .

Colombia, por su parte aun cuando requiere una reconversión del sector que se encuentra concesionado, la empresa privada Ferrovías cobra una tarifa que incluye: (a) gastos de operación; (b) gastos de conservación de la vía a un nivel adecuado de calidad y seguridad; (c) margen de utilidad; mientras que los costos de construcción de infraestructura o de rehabilitación de la misma están a cargo del Estado nacional, en virtud de considerar conveniente aplicar una política simétrica con el servicio de transporte automotor.

\section{Japón}

El Reino de Japón inaugura su primera línea en 1872, entre Shimbashi (Tokio) y Yokohama. Se inicio después que en Europa e incluso América. No es casual que en fueran los japoneses una de las delegaciones mas nutridas en presenciar la inauguración del subterráneo de Buenos Aires, en los albores del siglo XX.

Ahora bien, el desarrollo de Japón se presenta como formidable, en materia de conexión de pasajeros, ya que hoy cuenta con una malla de mas de 25 mil kilómetros de red, en una superficie total de poco mas de $377.000 \mathrm{~km} 2$, una densidad considerable, sobre todo por cuanto sirve esencialmente a la red de pasajeros. El sistema ferroviario es de alta sofisticación tecnológica y con acceso a todos los destinos del país, ya a través de las redes nacionales de transporte, reguladas por la

19 KOGAN, Jorge, Rieles con futuro. Desafío para los ferrocarriles de América del Sur, Corporación Andina del Fomento (CAF), caracas, Venezuela, 2004, p- 64. 
Japan National Railways (JNR), como las de larga distancia, conocidas como Shinkansen o "tren bala" que hoy lleva más del $90 \%$ de los pasajeros de larga distancia.

El Shinkansen, que constituyó en su día el primer Ferrocarril de alta velocidad, fue estrenado por la JNR en 1964. A finales de 1987, la compañía ya había construido 4 nuevas líneas de alta velocidad.

En esa época, se decide la privatización de los ferrocarriles mediante la colocación de acciones, lo que dio un avance mas gradual sobre las empresas.

En las ciudades japonesas alejadas de la metrópolis es posible encontrar empresas privadas de prestación de servicios de pasajeros.

La separación vertical propugnada en Europa no es aplicada en Japón, quien conjuga diversos criterios, permitiendo la integración vertical siempre que se trate de corredores pequeños y que sean autosustentables económicamente ${ }^{20}$.

A mi juicio, el logro de Japón se encuentra en la visión comprensiva de la problemática del transporte en el entorno social, económico y urbanístico. No se trato de una lucha de los modos carreteros y ferroviarios, sino de su integración en el espacio urbano, promoviendo el desarrollo de comercios, servicios, escuelas, hospitales, etc.

Así, conjugan la separación vertical de infraestructura y operación de servicios, por un lado, con la creación de sociedades (publicas o privadas) a cargo de unidades de negocios sustentables; y, por otro, no dejan de estudiar el impacto de las densidades poblacionales y las conexiones del ferrocarril con otros modos de servicio en la periferia de las ciudades ${ }^{21}$.

\footnotetext{
20 Ver en https://ruedaycarril.wordpress.com/2013/07/05/otros-mundos-ferroviarios-japon-i

21 Por ejemplo, Tokio tiene diversas ciudades satélites que fueron creadas para reducir la densidad poblacional, tales como Yokohama, garantizándose a los pobladores la existencia de servicios ferroviarios que rápidamente los comunique con sus lugares de trabajo en la ciudad principal.
} 
También se destaca la política en materia de educación para generarla conciencia en el administrado de abandonar el vehículo particular prefiriendo los transportes públicos ferroviarios o de buses.

\section{Conclusiones}

En estas notas pudimos ver en forma somera como se ha desarrollado el ferrocarril en el concierto internacional.

La coincidencia del nacimiento como negocio privado, por la alta rentabilidad que llevaba consigo, la luego impronta social del ferrocarril, y la aparición de aquel como servicio, en tanto a su vera se fueron construyendo ciudades y culturas lleva al Estado -cuando deja de ser un buen negocio para los privadosa adoptar un rol activo.

Las idas y vueltas de la gestión publica a lo privado, y viceversa, se van a dar en casi todos los países analizados, donde Japón, Estados Unidos y Francia, resaltan como los mas estables en sus políticas publicas, en tanto la incorporación del sector privado fue gradual en las empresas de servicios de pasajeros en la privatización de Japón; en Estados Unidos se mantiene desde los albores en manos de privados la explotación de las cargas transportadas, y el sector se estatizo para los servicios de pasajeros, pero con controles propios de empresas privadas, y Francia, que mantiene la presencia estatal, pero en divisiones orgánicas eficientes.

En los demás, veremos que luego de las crisis de estatización durante las dos grandes guerras y privatizaciones en los 90, la política de la separación vertical y horizontal ordena a buscar unidades de negocio sustentables.

Esto significa que hay que pensar en forma bifronte cuando del ferrocarril se trata, ya que, por un lado, es un servicio publico, una necesidad publica a cubrir, pero por el otro lado, es una unidad de negocio, que debe ser eficientemente gestionada, que no puede admitir dispendio, que debe optimizar la mejor manera 
de sostener su explotación. Sino tarde o temprano se produce su debacle y en esto el riesgo es muy grave.

Entre estas enseñanzas, surgen preclaras las reglas de la UNION EUROPEA que ordena sanear las economías de las empresas o entidades ferroviarias, distinguir las explotaciones ya en forma vertical como horizontal, sostener la infraestructura y garantizar la seguridad en su desarrollo e incorporar el sector privado, en las áreas que permitan sumar su valor agregado, y en la medida que se sostengan las primeras reglas indicadas.

Esto es, no más privado vs público como parámetro de solución mágica. En Argentina nos sobran los motivos para no sostener ese dogma.

Ahora bien, el control y la seguridad ferroviaria se eleva como un presupuesto básico.

No podrá avanzarse en nuevos esquemas si no se adoptan reglas de control eficiente y pautas homogéneas, por todos conocidas y por todas las entidades cumplidas. Un organismo de control que asuma su rol mas moderno, con la seguridad a su cargo. Este es otro de los puntos aun pendientes, que en Argentina como todo lo que ataña a la responsabilidad ha tenido un sino trágico.

Las Agencias americanas o europeas pueden ser de ejemplo. La necesidad de una entidad autónoma, técnica y que no este a expensas de los poderes de turno también es una condición esencial y de urgente aplicación en nuestro país.

Luego de restablecida la malla ferroviaria, asegurado sus servicios, se podrá pensar en el futuro, que es la integración de las redes, el denominado "Open Access" podrá permitir explotar en forma asociada entre los diferentes actores públicos y privados y en esto la sinergia de una de las actividades respecto a las otras aparece como conveniente. Pero reitero, a ello no se llega con un sistema descalabrado, sin reglas de ordenamiento claro, con empresas - reitero - publicas y privadas eficientes.

La formula es no tener una formula dogmática. 
La formula será, entonces, diseñar un sistema que primero revise los riesgos, luego ordene las actividades de infraestructura, servicios, explotaciones complementarias, urbanas, y comerciales, y que, en todos los casos, impongan buenas practicas ya para privados o públicos, ya que todos deben dar cuenta de sus actos mas allá de los negocios puntuales o de aquellos que permitan apalancar el desarrollo.

Mientras envío estas ideas para su publicación, se esta dando una pandemia, nunca vista desde la fiebre amarilla. Los sistemas ferroviarios se han ralentizado para sostener un servicio mínimo, por un lado y atender la salud publica, y por el otro lado, evitar la propagación del virus COVID - 19. El tiempo de reflexión que impone esta situación, quizás permita repensar el mejor camino, que no es la mera copia de lo que ocurre en el concierto internacional, pero por cierto, abreva en el, para mejor proyectar su solución vernácula.

Porque, el transporte ferroviario siempre se trata de una necesidad publica, de la atención del usuario, de un servicio para y por el publico. Que así sea. 